\title{
Symmetry of cerebral blood flow and cognitive responses to hypoglycaemia in humans
}

\author{
D.Kerr ${ }^{1}$, J.C. Stanley ${ }^{2}$, M. Barron ${ }^{2}$, R. Thomas ${ }^{2}$, B. A. Leatherdale ${ }^{1}$ and J. Pickard ${ }^{2}$ \\ I Department of Diabetes, Royal South Hants Hospital and ${ }^{2}$ Clinical Neurosciences Group, Southampton General Hospital, \\ Southampton, UK
}

\begin{abstract}
Summary. A low blood glucose level is associated with impairment of higher cerebral function and an increase in cerebral blood flow. This study examined whether there are differences in the physiological responses to hypoglycaemia between the cerebral hemispheres. Eight healthy men participated in two hyperinsulinaemic glucose clamp studies: after $60 \mathrm{~min}$ at $4.5 \mathrm{mmol} / \mathrm{l}$, blood glucose was either lowered to $2.0 \mathrm{mmol} / 1$ and "clamped" there for $60 \mathrm{~min}$ (hypoglycaemia) or continuously maintained at $4.5 \mathrm{mmol} / \mathrm{l}$ (euglycaemia). Cardiac output, middle cerebral artery velocity (transcranial Doppler) and cerebral blood flow (133-xenon inhalation) were measured during the studies. Neuropsychological tests were used to determine whether hypoglycaemia caused differential impairment of hemispheric cognitive function. Hypoglycaemia was associated with symmetrical impairment of cognitive function in both cerebral hemispheres and a rise in cardiac output (from 5.5 [0.2] to 8.7 [0.2] $1 \cdot \min ^{-1}, p<0.0001$, mean [standard error]), middle cerebral
\end{abstract}

artery velocity (from $55[2.6]$ to $64[2.8] \mathrm{cm} \cdot \mathrm{s}^{-1}, p<0.002$ ), and global cerebral blood flow (from 56 [2.6] to 69 [2.9] $\mathrm{ml} \cdot 100 \mathrm{~g}^{-1} \cdot \mathrm{min}^{-1}, \quad p<0.005$ compared to pre-insulin values). There were no differences in the blood flow response during hypoglycaemia between hemispheres and the increase in blood flow did not correlate with either the change in cardiac output or rise in plasma catecholamine levels. After $120 \mathrm{~min}$ of hyperinsulinaemic, euglycaemia, global cerebral blood flow rose significantly above baseline (from 58 [2.4] to 63 [2.2] $\mathrm{ml} \cdot 100 \mathrm{~g}^{-1} \cdot \mathrm{min}^{-1}, p<0.05$ ). In conclusion, using the techniques described, the physiological and cognitive responses of each cerebral hemisphere to hypoglycaemia were symmetrical. Hyperinsulinaemia, independent of blood glucose level, may be associated with an increase in cerebral blood flow.

Key words: Hypoglycaemia, cerebral hemispheres, cognitive function, cerebral blood flow.
The brain is almost totally dependent on a continuous supply of glucose from the peripheral circulation for normal function. As blood glucose levels fall below normal, tests of higher cerebral function deteriorate [1-3] and there is a concomitant rise in cerebral blood flow (CBF) [4]. Pathology studies suggest that not all areas of the central nervous system are equally vulnerable to the effects of a low blood glucose level [5]. Furthermore, focal transient neurological deficit, which is not obviously related to a structural abnormality, e.g. transient hemiplegia, may be associated with hypoglycaemia [6]. One possible explanation for these observations could be differential sensitivity of the blood flow responses within each cerebral hemisphere to hypoglycaemia.

The aim of this study was to investigate the effect of hypoglycaemia on blood flow between cerebral hemispheres. To determine whether the deterioration in cognition associated with hypoglycaemia "lateralizes" to one or the other side, a number of cognitive function tests were employed which may differentiate between higher function in each hemisphere. Only young men were recruited as cognitive function and hemispheric blood flow appear to be influenced by gender [7] and age [8].

\section{Subjects and methods}

Eight healthy men (aged 22-38 years) gave written consent for the study which had been approved by the hospital ethics committee. Each participated in two studies performed in a random order on 2 separate days at least 1 week apart.

After an overnight fast, subjects were studied in the recumbent position in a quiet room. Under local anaesthetic a cannula was placed in an ante-cubital vein of the non-dominant arm and a second, retrograde cannula inserted in a dorsal hand vein of the same arm, with the hand placed in a heated $\left(60^{\circ} \mathrm{C}\right)$ box. Patency was maintained by a constant infusion of $150 \mathrm{mmol} / 1 \mathrm{NaCl}$. After insertion of the cannulae, subjects rested supine for $20 \mathrm{~min}$ after which baseline (pre-insulin) measurements were made of: 


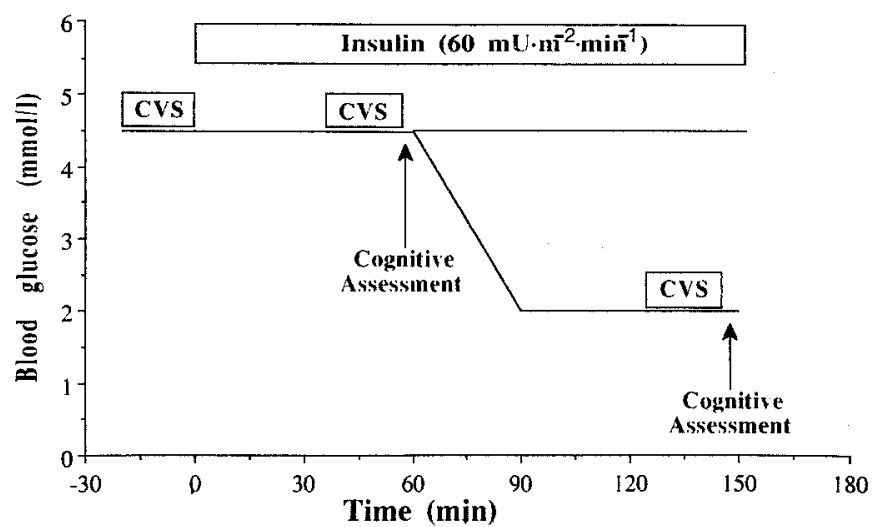

Fig.1. Schematic representation of the experimental protocol. Cardiovascular and cerebrovascular assessments (CVS) prior to starting the glucose clamp (baseline), during euglycaemia (60 min) and hypoglycaemia $(150 \mathrm{~min})$

Cardiac output by Doppler insonation of the ascending thoracic aorta (Quantascope; Siel Instruments, Bristol, UK) [9].

Right middle cerebral artery velocity using a transcutaneous Doppler technique (EME, Transcan, Uberslingen, FRG) [10].

Cerebral blood flow ( $C B F)$ measured using an inhalational 133xenon clearance technique (Novo Cerebrograph $32 \mathrm{C}$; Novo Diagnostic Systems, Bagsvaerd, Denmark). CBF was calculated using the initial slope index and the results averaged to calculate hemispheric and global means [11]. End tidal $\mathrm{pCO}_{2}$ was recorded during all measurements of CBF [12].

Blood pressure using an automated method (Accutor 1A; Datascope Corp, Newark, NJ, USA). Mean arterial pressure was calculated as diastolic blood pressure plus one-third of the difference between systolic and diastolic pressures.

Plasma catecholamine levels. Blood was taken from the heated hand vein, centrifuged at $4^{\circ} \mathrm{C}$ and $2000 \times g$ for $10 \mathrm{~min}$ and the plasma added to tubes containing $75 \mu \mathrm{l}$ EGTA-glutathione. Samples were stored at $-25^{\circ} \mathrm{C}$ for subsequent analysis by high performance liquid chromatography with electrochemical detection [13].

Following completion of the baseline (pre-insulin) measurements outlined above, a hyperinsulinaemic $\left(60 \mathrm{mU} \cdot \mathrm{m}^{-2} \cdot \min ^{-1}\right)$ glucose clamp technique [14] was used to maintain blood glucose at $4.5 \mathrm{mmol} / 1$ for $60 \mathrm{~min}$ using a constant infusion of human Actrapid insulin (Novo Laboratories) and a variable infusion of $200 \mathrm{~g} \cdot 1^{-1} \mathrm{dex}-$ trose (Fig.1). The dextrose infusion was adjusted according to bedside measurements of arterialised venous blood glucose taken at 5-min intervals on a Yellow Springs glucose analyzer (Yellow Springs Instrument Corp, Yellow Springs, Ohio, USA). During the final 10$20 \mathrm{~min}$ of this euglycaemic period the cardiovascular measurements listed above were repeated. In addition, hemispheric cognitive function was assessed by the following methods:

\section{Left dominant hemisphere}

1. Semantic processing [15] assesses ability to utilize stored information (semantic memory). The time taken to mark 50 statements (e.g. canaries have wings or canaries have gills) true or false was recorded. Different statements were used each time the test was administered to the same subject.

2. Word association [16] is an oral fluency test in which the subject says in one minute as many words as he can think of beginning with a given letter. Three letters of progressively increasing difficulty are presented successively. The difficulty level for each letter is determined from the frequency of words beginning with that letter as found in standard dictionaries.
3. Serial digit learning [17] assesses the ability to memorize nine randomly selected digits within a maximum of 12 attempts. The subject listens to the number twice and then attempts to repeat it back, scoring two points for a correct repeat. Once the criterion of two consecutive correct repetitions is reached and the task is discontinued, two points are given for each remaining trial up to and including the 12 th trial. The test score is the sum of the points obtained over 12 trials.

\section{Right hemisphere}

1. Face matching [18]. The face of a man or woman, without distinguishing marks, is presented to the subject (test face). Six faces which contain from one to three views of the face already seen are shown and the subject has to correctly identify the test face. The score is based on the number of correct identifications. The time taken to complete the task is also taken into account when assessing the score.

2. Unusual angles [19]. The subject has to identify common objects photographed from unusual angles. The score is dependent on the number of correct responses and time taken to complete the task.

3. Line orientation [20]. Subjects have to match a pair of lines of similar length, the angle between them varying by $15-180$ degrees, with an array of control lines arranged in a semi-circle. The score is equal to the number of correct matchings. The time taken to complete the task is also recorded.

After assessment of cognitive function, by adjusting the glucose infusion rate, blood glucose was either lowered over $30 \mathrm{~min}$ to $2.0 \mathrm{mmol} / \mathrm{l}$ and maintained there for $1 \mathrm{~h}$ (hypoglycaemic study) or clamped at $4.5 \mathrm{mmol} / \mathrm{l}$ for a further $90 \mathrm{~min}$ (euglycaemic study). This was done in a random order. A final set of vascular measurements and cognitive function assessments were repeated during the final $10-20 \mathrm{~min}$ of hypoglycaemia and at the corresponding time during the euglycaemic study.

\section{Statistical analysis}

Statistical analyses were performed using standard two and one-way tests of analysis of variance (ANOVA) for normally distributed data and Kruskal-Wallis test for skewed data. Where ANOVA showed significant differences between studies, contrasts in group means were compared with paired $t$-test or Wilcoxon signed rank tests as appropriate. Comparisons between variables were made using Spearman Rank Correlation analyses.

\section{Results}

Coefficients of variation for blood glucose level achieved during each study were less than $6 \%$ and the nadir blood glucose level during the hypoglycaemia study was $2.1[0.1] \mathrm{mmol} / 1$ (mean [standard error]). Insulin levels were similar in each study (144 [8.8] $\mathrm{mU} \cdot 1^{-1}$ during the euglycaemic study and $153[31.8] \mathrm{mU} \cdot 1^{-1}$ during the hypoglycaemic study). When blood glucose was lowered to $2.0 \mathrm{mmol} / 1$, all of the subjects developed characteristic symptoms (sweating, trembling, hunger and palpitations) and "felt hypoglycaemic".

\section{Cardiovascular and cerebrovascular assessments}

Cardiac output was similar at the start of both studies and did not change when blood glucose was "clamped" at $4.5 \mathrm{mmol} / \mathrm{l}$ (Fig. 2). When blood glucose was lowered to $2 \mathrm{mmol} / \mathrm{l}$, cardiac output rose markedly (from 5.5 [0.2] to $\left.8.7[0.2] 1 \cdot \mathrm{min}^{-1}, p<0.0001\right)$. Values for right middle 

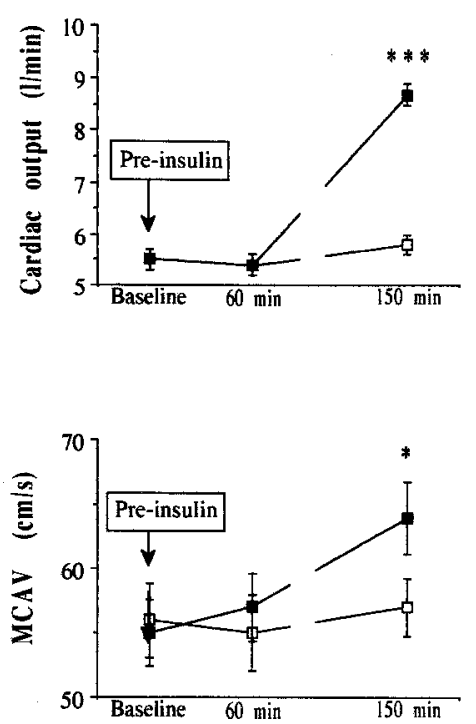

Fig. 2. Values (mean [standard error]) for cardiac output and middle cerebral artery velocity (MCAV) prior to starting the glucose clamp (baseline), during euglycaemia (60 min) and hypoglycaemia (150 min). * $p<0.002 * * * p<0.0001$ between studies. Q, Euglycaemia; $\square$, Hypoglycaemia
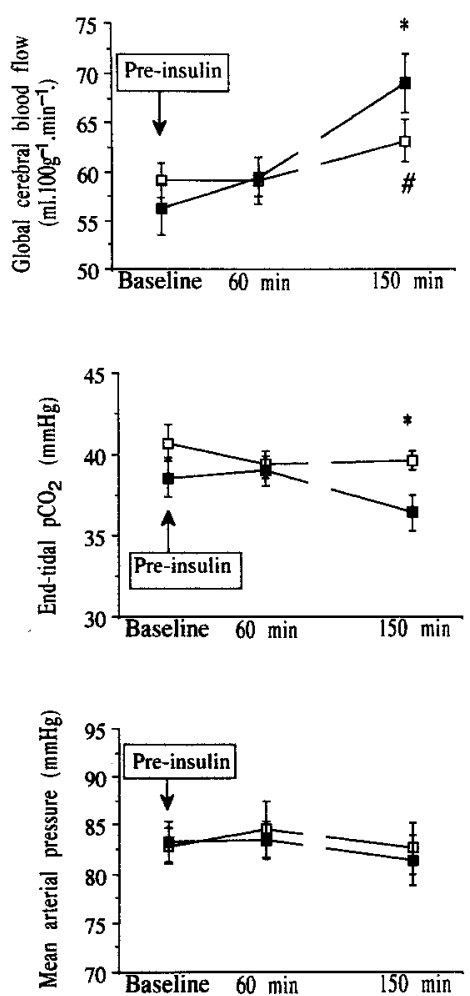

Fig. 3. Values (mean [standard error]) for global cerebral blood flow, end-tidal $\mathrm{pCO}_{2}$ and mean arterial pressure prior to starting the glucose clamp (baseline), during euglycaemia (60 min) and hypoglycaemia $(150 \mathrm{~min})$. ${ }^{*} p<0.05$ euglycaemia vs hypoglycaemia study and $\# p<0.05$ vs $60 \mathrm{~min}$ value. $\square$, Euglycaemia; $\square$, Hypoglycaemia

cerebral artery velocity (MCAV) were not different at baseline and did not change during euglycaemia (Fig. 2). In contrast to during euglycaemia, MCAV rose above baseline values when blood glucose was lowered to
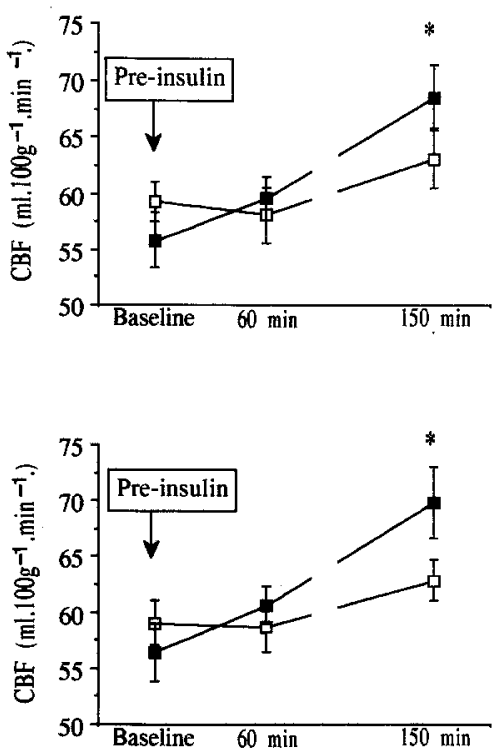

Fig.4. Values (mean [standard error]) for cerebral blood flow (CBF) in the right (upper panel) and left (lower panel) hemispheres prior to starting the glucose clamp (baseline), during euglycaemia (60 min) and hypoglycaemia (150 min). ${ }^{*} p<0.05$ between studies. $\square$, Euglycaemia; $\square$, Hypoglycaemia

$2 \mathrm{mmol} / 1$ (from $55[2.6]$ to $64[2.8] \mathrm{cm} \cdot \mathrm{s}^{-1}, p<0.002$ ). Mean arterial pressure did not change in either study (Fig. 3).

In both studies, values for global CBF were similar at baseline and did not change for the first $60 \mathrm{~min}$ (Fig. 3). However, in the euglycaemic study, global CBF rose significantly after $150 \mathrm{~min}$ (from $58[2.4]$ to $63.2[2.2] \mathrm{ml}$. $\left.100 \mathrm{~g}^{-1} \cdot \mathrm{min}^{-1}, p<0.05\right)$ in the absence of a change in blood glucose levels. In the hypoglycaemic study, global CBF increased when blood glucose was lowered to $2.0 \mathrm{mmol} / 1$ (from $56[2.6]$ to $69[2.9] \mathrm{ml} \cdot 100 \mathrm{~g}^{-1} \cdot \mathrm{min}^{-1}$, $p<0.005$ ), despite a fall in end-tidal $\mathrm{pCO}_{2}$ (Fig.3). The increase in global CBF during hypoglycaemia was greater than at the corresponding time during the euglycaemic study $(p<0.05)$. The changes in CBF were symmetical in both hemispheres (Fig.4).

Basal (pre-insulin) levels of plasma adrenaline $(0.2$ [0.1] vs $0.2[0.1] \mathrm{nmol} / 1)$ and noradrenaline $(1.3[0.3]$ vs $1.2[0.1] \mathrm{nmol} / 1)$ were similar at the start of each study. At the end of the euglycaemic period, adrenaline (0.2 [0.1] and $0.2[0.1] \mathrm{nmol} / \mathrm{l})$ and noradrenaline $(1.6[0.3]$ and $1.7[0.3] \mathrm{nmol} / \mathrm{l})$ levels were not significantly different from baseline in both studies. In the hypoglycaemia study, when blood glucose was lowered to $2.0 \mathrm{mmol} / \mathrm{l}$, adrenaline (to $6.4[1.2] \mathrm{nmol} / \mathrm{l}, p<0.0001$ ) and noradrenaline (to $2.7[0.3] \mathrm{nmol} / \mathrm{l}, p<0.02$ ) levels rose significantly above baseline, but were unchanged $(0.1[0.1] \mathrm{nmol} / \mathrm{l}$ and $1.6[0.3] \mathrm{nmol} / \mathrm{l}$ for adrenaline and noradrenaline respectively) at the end of the euglycaemic control study.

\section{Cognitive function}

The effects of continuous euglycaemia and hypoglycaemia on cognitive function tests are shown in Table 1. During continuous euglycaemia, both left and right hemi- 
Table 1. Cognitive function test results

\begin{tabular}{|c|c|c|}
\hline \multicolumn{3}{|l|}{ Left Hemisphere } \\
\hline \multirow[t]{2}{*}{ Semantic processing } & \multicolumn{2}{|c|}{ Time(s) taken to complete task } \\
\hline & Baseline & Change \\
\hline Euglycaemia study & $79[61,92]$ & $-8[-17,-3]$ \\
\hline Hypoglycaemia study & $81[61,92]$ & $+10[+2,+10]^{a}$ \\
\hline \multirow[t]{2}{*}{ Word association } & \multicolumn{2}{|c|}{ Number of words } \\
\hline & Baseline & Change \\
\hline Euglycaemia study & $52[40,57]$ & $+2[-1,+4]$ \\
\hline Hypoglycaemia study & $50[48,60]$ & $-13[-4,-17]^{a}$ \\
\hline \multirow[t]{2}{*}{ Serial digit learning } & \multicolumn{2}{|l|}{ Score } \\
\hline & Baseline & Change \\
\hline Euglycaemia study & $23[18,24]$ & $+1[-2,+4]$ \\
\hline Hypoglycaemia study & $22[19,24]$ & $-2[-5,+1]$ \\
\hline \multirow[t]{2}{*}{ Right Hemisphere } & \multicolumn{2}{|c|}{ Time(s) to complete each task } \\
\hline & Baseline & Change \\
\hline \multicolumn{3}{|l|}{ Face Matching } \\
\hline Euglycaemia study & $214[156,308]$ & $-55[-138,-13]$ \\
\hline Hypoglycaemia study & $195[136,238]$ & $+62[-29,+48]^{a}$ \\
\hline \multicolumn{3}{|l|}{ Unusual Angles } \\
\hline Euglycaemia study & $39[29,61]$ & $-6[-9,-1]$ \\
\hline Hypoglycaemia study & $32[21,55]$ & $-3[-5,+9]$ \\
\hline \multicolumn{3}{|l|}{ Line Orientation } \\
\hline Euglycaemia study & $43[39,71]$ & $+6[2,9]$ \\
\hline Hypoglycaemia study & $48[36,72]$ & $+7[-3,20]$ \\
\hline \multicolumn{3}{|c|}{${ }^{a} p<0.05$ euglycemia vs hypoglycaemia study. } \\
\hline \multicolumn{3}{|c|}{$\begin{array}{l}\text { Results from tests of cognitive function for each cerebral hemi- } \\
\text { sphere at baseline (blood glucose } 4.5 \mathrm{mmol} / \mathrm{l} \text { ) and during hypogly- } \\
\text { caemia (blood glucose } 2.0 \mathrm{mmol} / \mathrm{l} \text { ) and at the corresponding time } \\
\text { during the euglycaemia study. Results are expressed as median [in- } \\
\text { terquartile range]. Scores for each right hemisphere test did not sig- } \\
\text { nificantly change during euglycaemia (see Results). Time taken to } \\
\text { complete each right hemisphere task is shown. }\end{array}$} \\
\hline
\end{tabular}

sphere tests of cognitive function remained unchanged from baseline throughout the study. In contrast, when blood glucose was lowered to $2.0 \mathrm{mmol} / \mathrm{l}$, tests of left hemisphere function showed significant deterioration from baseline $(p<0.05)$ in semantic processing and word association but no change in serial digit learning. For the tests of right hemisphere cognition, actual scores for faces matching $(45[38,50]$ at baseline (median [interquartile range]) vs $43[35,49]$ at the end of the hypoglycaemic period), unusual angles $(7[5,8]$ vs $7[5,8])$ and line orientation $(14[12,14]$ vs $14[9,14])$ were unchanged, but the time taken to complete the faces matching task was significantly prolonged during hypoglycaemia $(p<0.05)$.

\section{Discussion}

It has been recognized for more than 100 years that when areas of the brain are functionally activated, brain blood flow increases and different aspects of mental and intellectual activity lateralize to one or the other cerebral hemisphere [21, 22]. Hypoglycaemia is associated with an increase in CBF but a deterioration in cognitive function [1-4]. The aim of this study was to determine whether the rise in blood flow or the impairment in cognitive function associated with a low blood glucose level "lateralize" to one or the other cerebral hemisphere. We found that cognitive function deteriorated similarly in both hemispheres, accompanied by a bilateral and symmetrical increase in $\mathrm{CBF}$, as blood glucose levels were lowered.

During moderate hypoglycaemia the increase in CBF involves both beta-adrenergic and non-beta-adrenergic mechanisms [23] without a change in cerebral autoregulation [24]. In this study the change in CBF was not correlated with the increase in cardiac output or levels of adrenaline and noradrenaline and there was no change in mean arterial blood pressure. The rise in CBF occurred in the presence of a fall in end-tidal $\mathrm{pCO}_{2}$ which normally attenuates the $\mathrm{CBF}$ response to a given stimulus [25]. Furthermore the magnitude of the $\mathrm{CBF}$ response to hypoglycaemia was significantly greater than the change in MCAV. The latter observation is not unexpected as velocity of flow is proportional to the square of vascular radius whereas, according to Poiseuille's equation, volume flow is proportional to the fourth power of the vascular radius [26]. The relationship between cardiac output and CBF is controversial. It has been suggested that increasing cardiac output in patients with cerebral ischaemia may be beneficial by increasing flow to the compromised area [27]. However Bouma and Muizelaar [28] found no correlation between cardiac output and $\mathrm{CBF}$ after multiple simultaneous measurements of both parameters in a group of patients with severe head injuries, irrespective of the state of cerebral autoregulation.

The increase in CBF in this study $(23 \%)$ is similar to that reported by Neil et al. [4] in diabetic patients (17\%) and healthy volunteers $(21 \%)$ using the intravenous xenon-clearance technique. The symmetry of the blood flow responses in the present study does not explain the transient focal neurological deficit which can be associated with hypoglycaemia in diabetic patients [6]. It has been suggested that this phenomenon may be due to localised loss of autoregulation or vasospasm and occurs in patients who have no evidence of a structural or vascular lesion [29]. It should be emphasized that we studied healthy volunteers. Patients with diabetes may have impairment of both cerebral autoregulation and reactivity of their cerebral blood vessels $[30,31]$. Recently Grill et al. [32] compared regional rates of CBF in Type 1 (insulindependent) diabetic patients and healthy control subjects during biostater-controlled euglycaemia. They reported higher global CBF values in the diabetic patients, with marked differences bilaterally in motor areas of the frontal lobes including the primary sensory-motor cortex as well as subcortical structures such as putamen and pons. However they found no evidence to support a direct effect of insulin on brain glucose consumption as hyperinsulinaemia did not significantly alter arterio-venous differences for glucose or oxygen. In the present study, hyperinsulinaemia, during euglycaemia, was associated with an increase in CBF after $150 \mathrm{~min}$. The delay in an insulin effect is consistent with the findings of Schwartz et al. [33] who examined the relationship between insulin levels in plasma and cerebrospinal fluid using hyperinsulinaemic glucose clamps in dogs. During sustained peripheral hyperinsulinaemia they reported that cerebrospinal fluid insulin levels did not alter during the first $60 \mathrm{~min}$ but 
thereafter rose in a dose-dependent fashion. Support for the concept of a direct effect of insulin on brain function comes from the recent observation that high insulin levels, independent of the prevailing blood glucose level, can attenuate the hormonal responses to and perception of hypoglycaemia in diabetic patients [34]. Alternatively insulin may indirectly increase CBF through activation of the sympathetic nervous system. Parts of the sympathetic nervous system might have been activated by hyperinsulinaemia [35, 36], despite the lack of a significant increase in plasma noradrenaline in the present study [37].

Mental activity is associated with an increase in CBF to both hemispheres [38]. Tasks involving language, verbal memory, speech, writing or arithmetic differentially increase flow to the dominant, usually left hemisphere, whilst tasks involving non-verbal skills such as facial recognition, visual memory and non-language environmental sounds lateralize to the non-dominant, usually right hemisphere [39]. In our study, during hypoglycaemia, cognitive assessment showed impairment of both hemispheres. However in the performance of right hemisphere tests, actual scores were not different from the results obtained during the euglycaemic study, but the time to complete the tests was significantly prolonged. It is possible that prolongation of answering time was due to inattention rather than a selective disturbance of the regions that are normally activated by the tests. In addition, the currently available tests of cognitive function may lack sufficient specificity and sensitivity to differentiate function in the two hemispheres. Laterality is relative, not absolute and does not correlate with invasive measures of cerebral asymmetry [40]. Furthermore, strategies that subjects adopt in neuropsychological assessments can alter performance i. e. repeated testing may not always produce the same result [40].

In conclusion hypoglycaemia is associated with a rise in $\mathrm{CBF}$ and impairment in higher cerebral function which is symmetrical between cerebral hemispheres. However the rise in CBF is independent of a change in cardiac output or circulating levels of catecholamines but may be modified by peripheral hyperinsulinaemia. Increasing evidence suggests that brain function may be influenced by the prevailing peripheral insulin level.

Acknowledgements. This study was supported by a generous grant from the Wessex Medical School Trust. We would like to thank Mr. P. Wood and Prof. I. A. Macdonald for measurement of plasma insulin and catecholamines and Dr. N. Kapur for help with the cognitive function tests.

\section{References}

1. Pramming S, Thorsteinsson B, Theilgaard A, Pinner E, Binder C (1986) Cognitive function during hypoglycaemia in type-1 diabetes mellitus. Br Med J 292: 647-650

2. Stevens AB, McKane WR, Bell PM, King DJ, Hayes JR (1989) Psychomotor performance and counterregulatory responses during mild hypoglycaemia in healthy volunteers. Diabetes Care 12: $12-17$

3. Kerr D, Macdonald IA, Tattersall RB (1989) Adaptation to mild hypoglycaemia in normal subjects despite sustained increases in counter-regulatory hormones. Diabetologia 32: 249-254

4. Neil HAW, Gale EAM, Hamilton SJC, Lopez-Espinoza I, Kaura R, McCarthy ST (1987) Cerebral blood flow increases during insulin-induced hypoglycaemia in type 1 (insulin-dependent) diabetic patients and control subjects. Diabetologia 30: 305-309

5. Auer RN, Siesjo BK (1988) Biological differences between ischemia, hypoglycaemia and epilepsy. Ann Neur 24: 699-707

6. Foster JW, Hart RG (1987) Hypoglycaemic hemiplegia: two cases and a clinical review. Stroke 18:944-946

7. Gur RC, Gur RE, Obrist WD et al. (1982) Sex and handedness differences in cerebral blood flow during rest and cognitive activity. Science 217: 659-661

8. Gur RC, Gur RE, Obrist WD, Skolnick BE, Reivich M (1987) Age and regional cerebral blood flow at rest and during cognitive activity. Arch Gen Psychiatry 44: 617-621

9. Huntsman LL, Gams E, Johnson CC, Fairbank SE (1978) Transcutaneous determination of aortic blood flow velocities in man. Am Heart J 89: 605-612

10. Aaslid R, Markwalder TM, Nornes H (1984) Non-invasive transcutaneous Doppler recording in basal cerebral arteries. J Neurosurg 57: 739-744

11. Obrist WD, Thompson HK, Wang HS, Wilkinson WE (1975) Regional cerebral blood flow estimated by 133-xenon inhalation. Stroke 6:245-256

12. Obrist WD, Wilkinson WE (1990) Regional cerebral blood flow measurement in humans by 133 -xenon clearance. Cerebrovasc Brain Metab Rev 2: 283-327

13. Macdonald IA, Lake DM (1985) An improved technique for extracting catecholamines from body fluids. J Neurosci Meth 13: 239-240

14. DeFronzo RA, Tobin JD, Andres R (1979) Glucose clamp technique: a method for quantifying insulin secretion and resistance. Am J Physiol 237: E214-E223

15. Baddeley A (1981) The cognitive psychology of everyday life. Brit J Psychol 72: 257-269

16. Benton AL, Hamsher K (1978) Multilingual aphasia examination. IV. Controlled word association. Benton Lab of Neuropsychology, University Hospitals, Iowa City, pp 13-15

17. Benton AL, Hamsher K de S, Varney NR, Spreen O (1983) Serial digit learning. In: Contributions to neuropsychological assessment, a clinical manual. Oxford University Press, Oxford, pp 23-29

18. Benton AL (1980) The neuropsychology of facial recognition. Am Psychol 35: 176-186

19. Warrington EK, Taylor AM (1973) The contribution of the right parietal lobe to object recognition. Cortex 9: 152-164

20. Benton AL, Varney NR, Hamsher K de S (1975) Judgement of line orientation. Form V. Benton Lab of Neuropsychology, University Hospitals, Iowa City

21. Broca $\mathbf{P}$ (1861) Remarques sur le siege de la faculte du language articule suives d'une obervation d'amphemie. Bull Social Anatomy Paris 6: 330-357

22. Roy CS, Sherrington MB (1890) On the regulation of the blood supply to the brain. J Physiol (London) 11: 85

23. Hollinger BR, Bryan RM (1987) B-receptor mediated increase in cerebral blood flow during hypoglycaemia. Am J Physiol 253: H $949-\mathrm{H} 955$

24. Sieber FE, Koehler RC, Derrer SA, Saudek CD, Traystman RJ (1990) Hypoglycaemia and cerebral autoregulation in anesthetized dogs. Am J Physiol 258: H1714-H1721

25. Kety S, Schmidt C(1946) The effects of active and passive hyperventilation on the cerebral blood flow, cerebral oxygen consumption, cardiac output and blood pressure of normal young men. J Clin Invest 25: 107-119

26. Rowan JO, Harper AM, Miller JD, Tedeschi GM, Jennett WB (1970) Relationship between volume flow and velocity in the cerebral circulation. J Neurol Neurosurg Psychiatry 33: 733738

27. Vander-Ark GD, Pomerantz M (1973) Reversal of ischemic neurological signs by increasing cardiac output. Surg Neurol 1: 257-258

28. Bouma GD, Muizelaar JP (1990) Relationship between cardiac output and cerebral blood flow in patients with intact and with impaired autoregulation. J Neurosurg 73:368-374 
29. Editorial (1985) Hypoglycaemia and the nervous system. Lancet II: $759-760$

30. Kastrup J, Rorsgaard S, Parving HH, Lassen NA (1986) Impaired autoregulation of cerebral blood flow in long-term type 1 (insulin-dependent) diabetic patients with nephropathy and retinopathy. Clin Physiol 6: 549-559

31. Dandona P, James IM, Newbury PA, Woollard ML, Beckett AG (1978) Cerebral blood flow in diabetes mellitus: evidence of abnormal cerebrovascular reactivity. Br Med J 2: 325-326

32. Grill V, Gutniak M, Bjorkman O et al. (1990) Cerebral blood flow and substrate utilisation in insulin-treated diabetic subjects. Am J Physiol 258: E 813-E820

33. Schwartz MW, Sipols A, Kahn SE et al. (1990) Kinetics and specificity of insulin uptake from plasma into cerebrospinal fluid. Am J Physiol 259: E378-E383

34. Kerr D, Reza M, Smith N, Leatherdale BA (1991) Importance of insulin in subjective, cognitive and hormonal responses to hypoglycaemia in patients with IDDM. Diabetes 40: 1057-1062

35. Anderson EA, Hoffman RP, Balon TW, Sinkey CA, Mark AL (1991) Hyperinsulinaemia produces both sympathetic neural activation and vasodilation in normal humans. J Clin Invest 87 : 2246-2252

36. Berne C, Pollare T, Fagius J (1989) The sympathetic outflow in vasoconstrictor nerve fascicles to muscle is increased during euglycaemic hyperinsulinaemia. Diabetologia 32: 465 A (Abstract)

37. Mitrakou A, Mokan M, Bolli G et al. (1992) Evidence against the hypothesis that hyperinsulinaemia increases sympathetic nervous system activity in man. Metabolism 41: 198-202

38. Gur R, Reivich M (1980) Cognitive task effects on hemispheric blood flow in humans: evidence for individual differences in hemispheric activation. Brain Language 9: 78-92

39. Kimura D (1973) The asymmetry of the human brain. Sci Am 228: $70-78$

40. Kolb B, Whishaw IQ (1985) Principles of cerebral asymmetry. In: Fundamentals of human neuropsychology, 2 nd edn. WH Freeman and Co, New York, pp 326-356

Received: 30 June 1992

and in revised form: 14 September 1992

Dr. D. Kerr

Diabetic Department

Royal United Hospital

Bath BA1 3NG

UK 